\title{
Deteksi Dini Peripheral Artery Disease melalui Pemeriksaan Ankle Brachial Index pada Kelompok Prolanis di Puskesmas Poasia
}

\section{Early Detection of Peripheral Artery Disease through Ankle Brachial Index Examination in Prolanist Group at Puskesmas Poasia}

\author{
Said, Asbath; Novianti, Asri Dwi; Fety, Yulli
}

Asbath Said asbath.mw@gmail.com Sarjana Keperawatan, Universitas Mandala Waluya, Indonesia, Indonesia

\section{Asri Dwi Novianti}

Sarjana Keperawatan, Universitas Mandala Waluya, Indonesia, Indonesia

\section{Yulli Fety}

Sarjana Keperawatan, Universitas Mandala Waluya, Indonesia, Indonesia

\section{Health Information: Jurnal Penelitian \\ Poltekkes Kemenkes Kendari, Indonesia \\ ISSN: 2085-0840 \\ ISSN-e: 2622-5905 \\ Periodicity: Bianual \\ vol. 13 no 1,2021 \\ jurnaldanhakcipta@poltekkes-kdi.ac.id}

Received: 17 February 2021

Accepted: 20 May 202

URL: http://portal.amelica.org/ameli/journal/504/5042198002/

DOI: https://doi.org/10.36990/hijp.v13i1.249

Corresponding author: asbath.mw@gmail.com

Authors retain copyright and grant the journal right of first publication with the work simultaneously licensed under a Creative Commons Attribution-ShareAlike 4.0 International License that allows others to share the work with an acknowledgment of the works authorship and initial publication in this journal and able to enter into separate, additional contractual arrangements for the nonexclusive distribution of the journals published version of the work (e.g., post it to an institutional repository or publish it in a book)

\section{(i) (2)}

This work is licensed under Creative Commons Attribution ShareAlike 4.0 International.
Ringkasan: Peripheral Artery Disease (PAD) merupakan komplikasi Diabetes Melitus (DM) Perubahan pada dinding pembuluh darah menyebabkan penurunan aliran darah (perfusi) ke ekstremitas bawah yang ditandai dengan penurunan ankle brachial index (ABI). Adapun tujuan penelitian ini adalah Mendapatkan gambaran Nilai ABI pada pasien diabetes di kelompok prolanis Di Puskesmas Poasia Kota Kendari Sulawesi Tenggara. Penelitian ini merupakan penelitian deskriptif, mendapatkan gambaran nilai ABI pada pasien dengan DM yang terdaftar sebagai pasien prolanis di puskemas poasia kendari sebanyak 14 orang. Hasil penelitian diperoleh yaitu: rata-rata berjenis kelamin adalah perempuan sebanyak 11 responden, rata-ata usia responden 46-55 tahun sebanyak 6 responden responden, dan rata-rata lama menderita responden adalah 0-2 tahun sebanyak 9 responden. Hasil penelitian yang diperoleh nilai ABI pada 14 pasien Diabetes Melitus tipe II (DM tipe II) masih banyak yang masuk dalam kategori normal yaitu sebanyak 9 responden $(64,3 \%)$ dan terdapat (35,7\%) responden memiliki ABI abnormal yaitu berada di kategori oklusi singan dan sedang. ABI normal pada responden dipengaruhi oleh rata-rata lama sakit DM hanya kurun waktu 5 tahun, hal tersebut yang menyebabkan nilai $\mathrm{ABI}$ dalam rentang normal dan belum banyak yang mengalami gangguan.

Kata kunci: Ankle brachial index, Diabetes melitus, Peripheral artery disease.

Abstract: Peripheral Artery Disease (PAD) is a complication of Diabetes Mellitus (DM). Changes in the walls of blood vessels cause a decrease in blood flow (perfusion) to the lower extremities which are marked by a decrease in the ankle-brachial index (ABI). The purpose of this study was to obtain an overview of $A B I$ values in diabetes patients in the prolanis group at Puskesmas Poasia, Kendari City, Southeast Sulawesi. This study is a descriptive study, to get an overview of the ABI value in patients with DM who were registered as prolanis patients at Poasia Kendari health center as many as 14 people. The results of the research were obtained, namely: the average gender was 11 respondents, the average age of the respondents was $46-55$ years old as many 
as 6 respondents, and the average length of suffering from the respondents was $0-2$ years as many as 9 respondents. The results of the study obtained ABI values in 14 patients with Type II Diabetes Mellitus (DM type II), there are still many who fall into the normal category, namely 9 respondents $(64.3 \%)$ and there are (35.7\%) respondents who have abnormal $\mathrm{ABI}$, namely in minor and moderate occlusion categories. Normal ABI in respondents is influenced by the average duration of diabetes mellitus is only a period of 5 years, this causes the $\mathrm{ABI}$ value in the normal range and not many have experienced disturbances.

Keywords: Ankle brachial index, Diabetes mellitus, Peripheral artery disease.

\section{PENDAHULUAN}

Pada tahun 2015 Indonesia berada di peringkat ke tujuh dunia dengan penderita Diabetes Melitus (DM) tertinggi setelah China, India, Amerika Serikat, Brazil, Rusia \& Meksiko (International Diabetes Federation, 2017). Prevalensi pengidap DM di Indonesia cenderung meningkat dari 5,7\% pada tahun 2007 dan 6, 9\% ditahun 2016 (Badan Penelitian dan Pengambangan Kesehatan, 2018).

Keadaan hiperglikemia kronis pada pengidap DM menimbulkan komplikasi yang bisa menimpa tiap sistem organ, salah satunya adalah kejadian aterosklerotik. Insiden aterosklerotik pada pembuluh darah besar di ekstremitas bertambah 2-3 kali (Shu \& Santulli, 2018). Gula di dalam darah yang meningkat akan mempengaruhi fungsi platelet sehingga terjadi pembekuan darah yang semakin lama akan meningkatkan risiko terhadap penyakit Peripheral Arterial Disease (PAD) yang umumnya terhubung dengan ekstremitas bawah (KohlmanTrigoboff, 2019). Penelitian menemukan jika seseorang yang menderita DM memiliki resiko terserang PAD 11,6 kali lebih besar dibanding yang tidak menderita DM (Rahman et al., 2012).

PAD merupakan gangguan suplai darah ke ekstremitas atas atau bawah karena obstruksi (Beshyah, 2014) dan mayoritas obstruksi disebabkan oleh aterosklerosis, namun dapat juga disebabkan oleh trombosis, emboli, vaskulitis, atau displasia fibromuskuler (Brady et al., 2014). Saat ini, diperkirakan lebih dari 202 juta orang di dunia menderita PAD dengan prevalensi pada individu dengan usia $\geq 40$ tahun adalah $4.3 \%$ dan usia $\geq 70$ tahun adalah $14,5 \%$ (World Health Organization, 2016). Prevalensi PAD di Indonesia pada satu juta orang Indonesia, 13.807 orang menderita PAD (Rhee et al., 2005).

Tanda-tanda utama PAD ialah claudication intermitten yaitu sensasi nyeri, pegal, kram, baal, atau tidak nyaman di otot yg terjadi ketika beraktivitas dan menghilang dengan istirahat nyeri muncul sebab suplai darah tidak bisa mencukupi kebutuhan jaringan yang meningkat pada waktu beraktivitas (Hinchliffe et al., 2020). Rasa nyeri umumnya timbul di sekelompok otot yang terletak distal berasal obstruksi arteri (Fowkes et al., 2017). Nyeri di pantat, pinggul dan paha merujuk kelainan pada segmen aorto-iliaka intermitten nyeri pada betis memberikan kelainan segmen femoral dan popliteal (Campia et al., 
2019). Intermittent claudication dapat terjadi di satu kaki saja (40\%) atau menyerang kedua eketremitas bawah (60\%) (Narula et al., 2018).

Untuk mendeteksi adanya PAD, salah satu metode yang dapat digunakan adalah mengukur Ankle Brachial Index (ABI). ABI digunakan sebagai indikator kapasitas fungsional pembuluh darah tungkai bawah dan sebagai prediktor morbiditas kardiovaskular dan mortalitas (Vrsalovic et al., 2017). Perubahan di dinding pembuluh darah mengakibatkan penurunan sirkulasi darah (perfusi) ke ekstremitas bawah yang ditandai adanya penurunan indeks ABI (Costa et al., 2017). ABI merupakan salah satu tindakan non invasif untuk menilai risiko penyakit kardiovaskular dalam perawatan primer (Maggi et al., 2014; Santosa \& Listiono, 2017). Alat yang digunakan untuk mengukur score ABI yaitu vascular doppler dengan frekuensi 5-10 MHz (Dana et al., 2014).

\section{METODE}

\section{Jenis Penelitian}

Penelitian ini merupakan penelitian kuantitatif dan desain deskriptif pada pengidap DM tipe 2 di Puskesmas Poasia Kota Kendari. Penelitian ini telah mendapatkan persetujuan etik dari komite etik Universitas Mandala Waluya dengan no. 023/UMW.XII/03/2020.

\section{Lokasi, Waktu, Populasi dan Responden}

Pengumpulan data dilakukan di Puskesmas Poasia Kendari yang dilaksanakan pada bulan Desember 2020. Populasi dalam penelitian pasien prolanis dengan DM tipe 2 yang terdaftar di puskemas poasia kendari sebanyak 14 orang. Teknik pengambilan sampel dalam penelitian ini adalah total sampling.

\section{Pengumpulan, Pengujian dan Analisis Data}

Nilai ABI diperoleh dengan cara membandingkan rasio tekanan darah sistol kaki dan tekanan darah sistol lengan. Pemeriksaan ini diukur pada pasien dengan posisi terlentang menggunakan Doppler vaskuler dan sphygmomanometer. Interpretasi nilai Ankle Brachial Index (ABI) adalah sebagai berikut: normal (0.91-1,30); oklusi ringan (0,70-0,90); oklusi sedang $(0,40-0,69)$; oklusi berat $(<0,40)$. 


\section{HASIL}

Tabel 1

Deskriptif karakteristik responden

\begin{tabular}{|c|c|c|}
\hline Karakteristik Responden & Jumlah (N=14) & Persentase (100\%) \\
\hline \multicolumn{3}{|l|}{ Jenis kelamin| } \\
\hline Laki-laki & 3 & 21,4 \\
\hline Perempuan & 11 & 78,6 \\
\hline \multicolumn{3}{|l|}{ Kelompok umur (tahun) } \\
\hline $36-45$ & 4 & 28,6 \\
\hline $46-55$ & 6 & 42,9 \\
\hline $56-65$ & 3 & 21,4 \\
\hline$>65$ & 1 & 7,1 \\
\hline \multicolumn{3}{|l|}{ Pekerjaan } \\
\hline Tidak bekerja & 6 & 42,9 \\
\hline Wiraswasta & 6 & 42,9 \\
\hline PNS & 2 & 14,3 \\
\hline \multicolumn{3}{|l|}{$\begin{array}{l}\text { Lama menderita DM } \\
\text { (tahun) }\end{array}$} \\
\hline $0-2$ & 9 & 64,3 \\
\hline $2,1-4$ & 2 & 14,3 \\
\hline $4,1-6$ & 3 & 21,4 \\
\hline \multicolumn{3}{|l|}{$\begin{array}{l}\text { Nilai ABI ekstremitas } \\
\text { kanan }\end{array}$} \\
\hline Oklusi sedang & 2 & 14,3 \\
\hline Oklusi ringan & 3 & 21,4 \\
\hline Normal & 9 & 64,3 \\
\hline \multicolumn{3}{|l|}{ Nilai ABI ekstremitas kiri } \\
\hline Oklusi sedang & 1 & 7,1 \\
\hline Oklusi ringan & 3 & 21,4 \\
\hline Normal & 10 & 71,4 \\
\hline
\end{tabular}

DOI: https://doi.org/10.36990/hijp.v13i1.249.g536

Responden terbanyak dari gender perempuan (78,6\%), lebih dari setengah (42\%) responden berusia 46-55 tahun, respondenyang masih produktif bekerja dan yang tidak bekerja dengan persentase sama (42,9\%). Responden yang lamanya menderita DMantara 0-2 tahun pada 64,3 persen ( 9 orang). interpretasi nilai ABI ekstremitas kanan dan kiri terbanyak normal (64,3\% \& 71,4\%). 
Tabel 2

Nilai ABI dari pemeriksaan kedua esktremitas berdasarkan lamanya menderita DM

\begin{tabular}{|c|c|c|}
\hline Nilai ABI & $\prec 3$ tahun & $\geq 3$ tahun \\
\hline \multicolumn{3}{|l|}{ Ekstremitas kanan } \\
\hline Normal & $6(75,0 \%)$ & $3(50,0 \%)$ \\
\hline Oklusi ringan & $2(25,0 \%)$ & $1(16,6 \%)$ \\
\hline Oklusi sedang & $0(0,0 \%)$ & $2(33,4 \%)$ \\
\hline \multicolumn{3}{|l|}{ Ekstremitas kiri } \\
\hline Normal & $5(62,5 \%)$ & $2(33,4 \%)$ \\
\hline Oklusi ringan & $3(37,5 \%)$ & $3(50,0 \%)$ \\
\hline Oklusi sedang & $0(0,0 \%)$ & $1(16,6 \%)$ \\
\hline
\end{tabular}

DOI: https://doi.org/10.36990/hijp.v13i1.249.g537

Pada esktremitas kanan dengan lamanya menderita DM kurang dari tiga tahun, oklusi normal terlihat mayoritas terjadi dengan frekuensi 6 responden (75\%), demikian juga pada pemeriksaan di ekstremitas kiri dengan nilai normal pada 5 responden (62,5\%). Nilai ABI pada responden yang menderita DM lebih dari tiga tahun, terjadi oklusi yang bervariasi pada pemeriksaan kedua ekstremitas.

\section{Tabel 3}

Nilai ABI dari pemeriksaan kedua ekstremitas berdasarkan usia penderita DM

\begin{tabular}{|c|c|c|}
\hline Nilai ABI & $\prec \mathbf{5 0}$ tahun & $\geq \mathbf{5 0}$ tahun \\
\hline \multicolumn{3}{|l|}{ Ekstremitas kanan } \\
\hline Normal & $3(60,0 \%)$ & $6(66,7 \%)$ \\
\hline Oklusi ringan & $2(40,0 \%)$ & $1(11,1 \%)$ \\
\hline Oklusi sedang & $0(0,0 \%)$ & $2(22,2 \%)$ \\
\hline \multicolumn{3}{|l|}{ Ekstremitas kiri } \\
\hline Normal & $2(40,0 \%)$ & $5(55,6 \%)$ \\
\hline Oklusi ringan & $3(60,0 \%)$ & $3(33,3 \%)$ \\
\hline Oklusi sedang & $0(0,0 \%)$ & $1(11,1 \%)$ \\
\hline
\end{tabular}

DOI: https://doi.org/10.36990/hijp.v13i1.249.g538

Hasil pemeriksaan esktremitas kanan pada responden usia kurang dari 50 tahun adalah terjadi oklusi ringan (40\%) sedangkan pada ekstremitas kiri, oklusi ringan pada 60 persen responden. Terdapat oklusi ringan-sedang pada responden yang berusia lebih dari 50 tahun baik pada kedua tempat pemeriksaan.

\section{PEMBAHASAN}

Distribusi reponden berdasarkan jenis kelamin adalah mayoritas responden berjenis kelamin perempuan $(78,6 \%)$ dan responden laki-laki sebanyak 3 responden $(21,4 \%)$ (Tabel 1). Beberapa literatur menghubungkan bahwa prevalensi diabetes melitus tipe 2 lebih banyak diderita oleh wanita dari pada laki-laki. Keterkaitan wanita dengan DM tipe 2 berhubungan dengan multifaktorial, seperti regulasi insulin yang dihubungkan dengan hormon 
estrogen dan progesteron, penggunaan kontrasepsi hormonal, asupan makanan dan status gizi serta distribusi lemak dalam tubuh yang terkait dengan resistensi insulin (Rosenberg et al., 2012).

Berdasarkan hasil penelitian (Tabel 2) diperoleh nilai ABI untuk ekstremitas kanan terbanyak yaitu normal $(\geq 0,95)$ sebanyak 9 orang $(64,3 \%)$ dan untuk ekstremitas kiri terbanyak yaitu normal 10 orang $(71,4 \%)$. Hal ini berkaitan dengan prevalensi lama menderita DM kurang dari tiga tahun. Dan pada reponden yang telah menderita DM lebih dari empat tahun, sebanyak 3 orang $(21.4 \%)$ mengalami oklusi ringan dan 2 orang $(14.2 \%)$ responden pada pengukuran $\mathrm{ABI}$ di ekstremitas kanan, selain itu 1 orang responden $(7,1 \%)$ orang yang mengalami oklusi sedang pada pengukuran ABI di ektremitas kiri. Lamanya menderita DM berhubungan dengan kejadian oklusi yang dialami oleh penderita (Cahyono \& Purwanti, 2019; Lintang S et al., 2019).

Peneliti berasumsi bahwa nilai ABI normal pada responden (Tabel $2 \&$ Tabel 3) dipengaruhi oleh rata-rata lama sakit DM hanya kurun waktu 5 tahun, hal tersebut yang menyebabkan nilai ABI dalam rentang normal dan belum banyak yang mengalami gangguan (Hinchliffe et al., 2020).

Penurunan nilai ABI akan menyebabkan komplikasi nekrotik yang mengganggu aliran darah ke ekstrimitas bawah (Hinchliffe et al., 2020). Lama menderita DM tipe dua meningkatkan penumpukan glukosa pada darah yang menyebabkan kerusakan pada pembuluh darah, sehingga menimbulkan risiko terjadinya komlikasi yang umumnya akan ada pada 5-10 tahun. Ada hubungan antara lama menderita DM dengan gangguan peredaran darah pada jaringan perifer (Hicks \& Selvin, 2019) dan kejadian ini sedikit banyak dapat mempengaruhi kualitas hidup penderita DM (Barshes \& Grant, 2019; Santosa $\&$ Listiono, 2017). Sebagai bentuk pencegahan, menjaga asupan makanan (Irma, 2019) dan melakukan olah raga (Rahayu et al., 2017).

\section{KESIMPULAN DAN SARAN}

Hasil penelitian ini memberikan gambaran tentang nilai ABI pada pasien DM Tipe 2 yang tergabung dalam kelompok Prolanis Puskesmas Poasia Kendari. Agar Pasien mulai menyadari pentingnya diagnosis dini dengan pengukuran nilai ABI untuk menilai penyakit vaskular Perifer.

Saran bagi Puskesmas agar menjadikan pemeriksaan ABI sebagai bentuk pemeriksaan berkala untuk mengetahui kemungkinan terjadinya PAD pada pasien Diabetes Mellitus. Bagi peneliti selanjutnya disarankan perlu dilakukan pemeriksaan kadar glukosa darah, $\mathrm{HbAlc}$, trigliserida, dan kolesterol, dan dianalisis lebih lanjut dampaknya terhadap nilai $\mathrm{ABI}$ dan menggunakan sample yang lebih banyak.

\section{Kekuragan Penelitian}

Penelitian menggunakan sampel yang sedikit dan metode yang digunakan bersifat deskriptif belum menghubungkan dengan variabel lain sehingga dalam mengeneralisasi hasil perlu kehati-hatian karena sampel yang sangat sedikit. 


\section{DAFTAR PUSTAKA}

Badan Penelitian dan Pengambangan Kesehatan. (2018). Hasil Utama Riset Kesehatan Dasar (Riskesdas) 2018. Kementerian Kesehatan

Barshes, N. R., \& Grant, C. L. (2019). Advances in the management of peripheral artery disease. Current Diabetes Reports, 19(7), 1-7. https://doi.org/10.1007/s11892-0 19-1155-0

Beshyah, S. (2014). Textbook of diabetes. In R. I. G. C. S. C. M. F. M. J. G. M. HOLT (Ed.), Ibnosina Journal of Medicine and Biomedical Sciences, 3(4).

Brady, A-M., McCabe, C \& McCann, M. (2014). Fundamentals of Medical-Surgical Nursing: A Systems Approach. Wiley Backwell

Cahyono, T. D., \& Purwanti, O. S. (2019). Hubungan Antara Lama Menderita Diabetes Dengan Nilai Ankle Brachial Index. Jurnal Berita Ilmu Keperawatan, 12(2), 65-71.

Campia, U., Gerhard-Herman, M., Piazza, G., \& Goldhaber, S. Z. (2019). Peripheral artery disease: past, present, and future. The American Journal of Medicine, 132(10), 1133-1141.

Costa, R. H. R., Cardoso, N. A., Procópio, R. J., Navarro, T. P., Dardik, A., \& de Loiola Cisneros, L. (2017). Diabetic foot ulcer carries high amputation and mortality rates, particularly in the presence of advanced age, peripheral artery disease and anemia. Diabetes \& Metabolic Syndrome: Clinical Research \& Reviews, 11, S583S587. https://doi.org/10.1016/j.dsx.2017.04.008

Dana, S., Crăciunescu, M., Fulger, L., Anastasiu, D., \& Craina, M. (2014). Conventional, Doppler Ultrasound and Real Time Elastography in Diagnostic of Thyroid Solitary Nodules. Advances in Cancer Research \& Treatment, Vol. 2014 (2014).

Fowkes, F. G. R., Aboyans, V., Fowkes, F. J. I., McDermott, M. M., Sampson, U. K. A., \& Criqui, M. H. (2017). Peripheral artery disease: epidemiology and global perspectives. Nature Reviews Cardiology, 14(3), 156.

Hicks, C. W., \& Selvin, E. (2019). Epidemiology of peripheral neuropathy and lower extremity disease in diabetes. Current Diabetes Reports, 19(10), 1-8.

Hinchliffe, R. J., Forsythe, R. O., Apelqvist, J., Boyko, E. J., Fitridge, R., Hong, J. P., Katsanos, K., Mills, J. L., Nikol, S., \& Reekers, J. (2020). Guidelines on diagnosis, prognosis, and management of peripheral artery disease in patients with foot ulcers and diabetes (IWGDF 2019 update). Diabetes/Metabolism Research and Reviews, 36, e3276.

International Diabetes Federation. (2017). IDF Diabetes Atlas Eighth edition 2017. In International Diabetes Federation. IDF Diabetes Atlas, 8th edn. Brussels, Belgium: International Diabetes Federation, 2017. http://www.diabetesatlas.org

Irma, R. (2019). Identifikasi faktor yang berhubungan dengan kejadian diabetes melitus di kabupaten konawe provinsi sulawesi tenggara. Health Information\#: Jurnal Penelitian, 11(2), 145-153. https://doi.org/10.36990/hijp.v11i2.139

Kohlman-Trigoboff, D. (2019). Update: Diagnosis and management of peripheral arterial disease. The Journal for Nurse Practitioners 15(1).

Lintang S, A. A., Mutiara, H., Sari, M. I., Muhartono, M \& Falamy, R. (2019). Hubungan Antara Lama Menderita Diabetes Melitus Tipe 2 Dengan Kejadian Peripheral Arterial Disease Pada Pasien Diabetes Melitus Tipe 2 Di Puskesmas Kedaton Kota Bandar Lampung. MEDULA, Medicalprofession Journal of Lampung University, 9(2), 379-384. 
Maggi, D. L., Quadros, L. R. D. P. de, Azzolin, K. de O., \& Goldmeier, S. (2014). Anklebrachial index: nurses strategy to cardiovascular disease risk factors identification. Revista Da Escola de Enfermagem Da USP, 48(2), 223-227.

Narula, N., Dannenberg, A. J., Olin, J. W., Bhatt, D. L., Johnson, K. W., Nadkarni, G., Min, J., Torii, S., Poojary, P., \& Anand, S. S. (2018). Pathology of peripheral artery disease in patients with critical limb ischemia. Journal of the American College of Cardiology, 72(18), 2152-2163.

Rahayu, D. Y. S., Pertami, S. B., \& Budiono, B. (2017). Kadar gula darah dan senam sehat diabetes mellitus. Health Information\#: Jurnal Penelitian, 9(2), 50-57. htt ps://doi.org/10.36990/hijp.v9i2.72

Rahman, A., Limantoro, C., \& Purwoko, Y. (2012). Faktor-Faktor Risiko Mayor Aterosklerosis pada Berbagai Penyakit Aterosklerosis di Rsup Dr. Kariadi Semarang. Jurnal Kedokteran Diponegoro, I (1).

Rhee, S. Y., Oh, S., Young-Seol, K., \& Young-Kil, C. (2005). Peripheral Arterial DiseaseScreening and Evaluation of Diabetic Patients in Asian Regions Characterized by High Risk Factros (PAD-SEARCH): Korean Subreport. Diabetes, 54, A250.

Rosenberg, R. N., Longo, D. L., Fauci, A. S., Kasper, D. L., Hauser, S. L., Jameson, J. L., \& Loscalzo, J. (2012). Harrison's Principles of Internal Medicine.

Santosa, A., \& Listiono, D. (2017). Prediksi score Ankle Brachial Index (ABI) ditinjau dari tanda gejala peripheral arterial disease (PAD). Medisains, 15(2), 118-128.

Shu, J., \& Santulli, G. (2018). Update on peripheral artery disease: Epidemiology and evidence-based facts. Atherosclerosis, 275, 379-381. https://doi.org/10.1016/j.at herosclerosis.2018.05.033

Vrsalovic, M., Vucur, K., Vrsalovic Presecki, A., Fabijanic, D., \& Milosevic, M. (2017). Impact of diabetes on mortality in peripheral artery disease: a meta - analysis. Clinical Cardiology, 40(5), 287-291.

World Health Organization. (2016). Global Report on Diabetes.

\section{Catatan kaki}

Catatan Penerbit Poltekkes Kemenkes Kendari menyatakan tetap netral sehubungan dengan klaim atas perspektif atau buah pikiran yang diterbitkan dan dari afiliasi institusional manapun.

Pernyataan Konflik Kepentingan Para penulis menyatakan tidak terdapat konflik kepentingan.

Kontribusi Penulis Para penulis tidak mendeklarasikan kontribusinya.

Berbagi Data Data hasil kajian disimpan pada komunitas health information : jurnal penelitian data sharing dan dapat dikunjungi melalui https://doi.org/10.5281/zenodo.5011171.

\section{Author notes}

asbath.mw@gmail.com 